\title{
Automated Sensory Monitoring System Prototype for Continuous Monitoring of Material and Structure State
}

\author{
1st Maris Hauka \\ Institute of Aeronautics \\ Riga Technical University \\ Riga, Latvia \\ maris.hauka@rtu.lv \\ $4^{\text {th }}$ Raivis Kubulins \\ Institute of Aeronautics \\ Riga Technical University \\ Riga, Latvia \\ raivis.kubulinsh@inbox.lv
}

\author{
$2^{\text {nd }}$ Vitālijs Pavelko \\ Institute of Aeronautics \\ Riga Technical University \\ Riga, Latvia \\ vitalijs.pavelko@rtu.lv \\ $3^{\text {rd }}$ Ilmars Blumbergs \\ Institute of Aeronautics \\ Riga Technical University \\ Riga, Latvia \\ ilmars.blumbergs@rtu.lv
}

\begin{abstract}
The goal of this article is to solve problems of automated monitoring systems of industrial and aviation constructions. Based on the latest research results, the most cost-effective solutions are covered, and a practical solution is offered. This article is part of the scientific project "Development of an integrated sensor system for material and structure monitoring". The article describes the problem and suggests a practical solution for an integrated sensor system for material and structure monitoring prototype.
\end{abstract}

Keywords - Non-destructive testing, integrated monitoring, piezoelectric sensor, impedance.

\section{INTRODUCTION}

Monitoring of constructions is made "all the time", that is to say - any interval deemed necessary; from the point of view of statistics - when the variable "chance the construction would crash" meets the variable "this much money can be spent on inspection". So, some faults could still occur. Manufacturing plants stop, trains break and even derail, bridges crumble and collapse, aircrafts fail and even crash. To make such occurrences less often and less severe, automated monitoring systems should be introduced. Systems that would really be able to monitor all the time - constantly and without any intervals; this would let us know when the first sign of a budding problem occurs instead of how it has to be done immediately - the best that can be done with manual maintenance at intervals - if luck allows it, to find actual problems that have already appeared or even clustered together, forming a bigger problem [1],[2],[4]-[6] Inventing and introducing such systems always come with certain limitations. Firstly - the system should be safe, secondly - the monitoring system should cost considerably less than the object it will be monitoring. This article will evaluate methods that can be used to monitor the state of constructions and the base elements, the sensory elements used for these methods, and offer a practical solution. The project objective is expected to develop a new technology which is mainly based on the reference-free principle of assessment of the monitoring results. A prerequisite for the successful solution of this problem is the results of recent original studies concerning the structure/sensor loading effects on the interaction of ultrasonic waves with structural defects.

\section{FULL ELECTROMECHANICAL IMPEDANCE METHOD}

A rather new method is the electromechanical impedance or full resistance (impedance) (EMI) method. The method entails scanning the sample with sound waves in a specific frequency range and the sensors then read the signature of the sample. If the state of the sample changes, so does the signature. This method is not particularly widespread. The tools to use the EMI method for now are comparatively expensive and to actually use it an extensive knowledge base is needed regarding the signature of material, as the signature is affected by various conditions, such as load, microfractures and also ambient sound; if the material can soak up humidity, the humidity level will also affect the signature. Lately, more acceptable solutions can already be found on the market both in terms of the price of the equipment and availability of databases. The databases are based on research performed with those devices and have data such as, for example,

Online ISSN 2256-070X

https://doi.org/10.17770/etr2021vol2.6660

(C) 2021 Maris Hauka, Vitālijs Pavelko, Ilmars Blumbergs, Raivis Kubulins

Published by Rezekne Academy of Technologies.

This is an open access article under the Creative Commons Attribution 4.0 International License. 
the suggested frequency range for concrete construction depending on the depth of the scan required [8].

\section{NDT SOLUTION}

The most commonly used simple EMI system is based on an impedance converter, see Fig. 1, as the AD5933 1 MSPS, a 12Bit converter and its evaluation hardware EVAL-AD5933EBZ. The pros of this system are its comparatively low price, industrial temperature range of $-40{ }^{\circ} \mathrm{C}$ to $+125^{\circ} \mathrm{C}$; $2.7 \mathrm{~V}$ to $5.5 \mathrm{~V}$ power supply operation and the serial I2C interface, which allows the elements not only be linked to a computer system, but also microcontroller systems, thus making the whole system configuration and system costs more flexible [7].
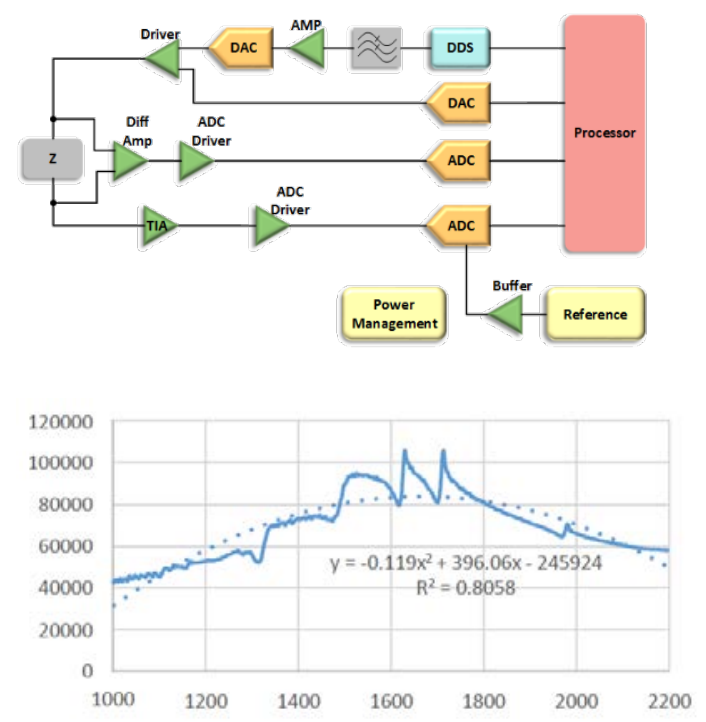

Fig. 1 Impedance Converter (upper image) and (lower image) impedance $(\Omega)$ depending on frequency $(\mathrm{Hz})$ output graph.

Such microchips are mostly intended for medical or network uses, so they are not ideal for use in construction monitoring. But, if the automated monitoring systems based on this method were to become more commonplace, then the specialized systems should also become more available. During the research (Venu Gopal Madhav Annamdas, Yaowen Yang, Chee Kiong Soh,2010) [8], testing of concrete constructions was commenced using an Embedded PZT Sensor; the research confirmed that $100 \mathrm{kHz}$ frequency was optimal for the tests on the concrete and the maximum measurement range was $200 \mathrm{~mm}$. Since the chip can measure only the resistance, but not the capacitance or inductance, it is therefore necessary to take into account the expected circuit diagram of the PZT model. This model can be formed from resistors, capacitors and inductors using appropriate equations (1), (3), (2).

$$
\begin{aligned}
& Z_{R}=R \\
& Z_{L}=L w j \\
& \left|Z_{L M A X}\right|=2 \pi f_{M A X} L \\
& \left|Z_{\text {LMIN }}\right|=2 \pi f_{M I N}^{L}
\end{aligned}
$$

$$
\begin{aligned}
& Z_{C}=\frac{1}{C w j} \\
& \left|Z_{\text {CMAX }}\right|=\frac{1}{2 \pi f_{M I N} C} \\
& \left|Z_{\text {CMIN }}\right|=\frac{1}{2 \pi f_{M A X} C}
\end{aligned}
$$

To improve accuracy based on the manufacturer's recommendations, the following equations (4) can be used to obtain more accurate impedance $\mathrm{Z}$ measurement results.

$$
\begin{aligned}
& Z=M \times X \times C \\
& M=\frac{\left(Z_{M A X}-Z_{M I N}\right)}{\left(X_{M A X}-X_{M I N}\right)} \\
& C=Z_{M I N}-\left(M-X_{M I N}\right)
\end{aligned}
$$

Where:

$\mathrm{Z}_{\mathrm{MAX}}$ is the real maximum impedance.

$\mathrm{Z}_{\mathrm{MIN}}$ is the real minimum impedance.

$\mathrm{X}_{\mathrm{MAX}}$ is the maximum measured impedance.

$\mathrm{X}_{\mathrm{MIN}}$ is the minimum measured impedance.

\section{SMALL SINGLE-BOARD COMPUTERS AND PROTOTYPE}

Various applicable elements where revised and each had its strong and weak points. Among them, the following minicomputers where found to be the most optimal - see below.

With the creation of a popular company, the Raspberry Pi Zero $\mathrm{W}$ minicomputer can work with various available operating systems as well as a self-made one. They are promoted as a \$5 device, although it costs $\$ 25$ to acquire one. The leading advantage of this solution is its small size; it has Bluetooth 4.0 and is wireless network compatible. It consumes 100-350 mA on average, which can be considered as very efficient. Logic works with $3.3 \mathrm{~V}$, which allows for a wide variety of auxiliary modules and elements that can be used in conjunction. A somewhat similar creation of another company - the Orange Pi Zero Plus an upgraded version of the Orange Pi Zero, has no power over ethernet (POE), making it a less attractive option for the prototype. The latest generation Raspberry $\mathrm{Pi} 4$ is a reliable solution all-round, but its power consumption is higher than the others, as it has integrated a powerful video graphic module, which is a completely useless element in the project, just like its support of USB 3.0, as sufficient LTE can be ensured via USB 2.0. A study of LTE problems is discussed in the article [9]. As a result, for this project at this phase of research, the less known Orange Pi zero is more viable. An additional downside of this module can also be noted, which is that the components are not the latest generation and as it is not a large company, the technical support is subpar. Even though the Orange Pi zero by default can support POE (though is not preinstalled), it only provides up to $5 \mathrm{~V}$ max. for it. It is obviously insufficient for long range communications. The majority of POE injectors have $24 \mathrm{~V}$ or more as their operating voltage. Studying the schematic allowed one to make the conclusion that it is possible to modify the board to provide higher POE values. 


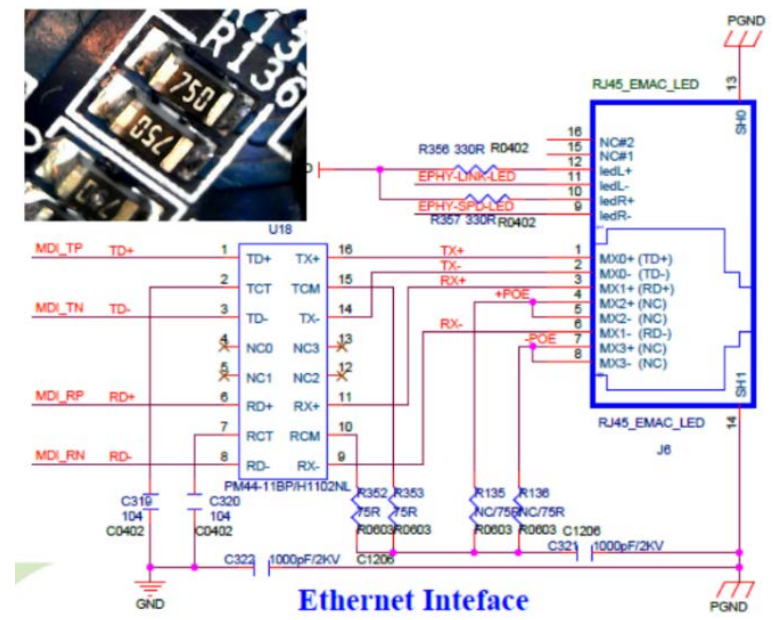

Fig. 2. Power over Ethernet (POE) of the Orange Pi zero.

Explanation of the required modifications to increase POE voltage: According to the schematic, both POE+ and POE- pins are connected to the GND through $750 \Omega$ resistors (R136 and R135 in Fig. 2). In the case that higher voltage would to be provided to this junction, it would lead to either or even all of the following: burning out of the resistors; burning of the electrical pathways of the circuit board; or power supply malfunction. Since higher voltage is a must, these resistors will need to be removed.
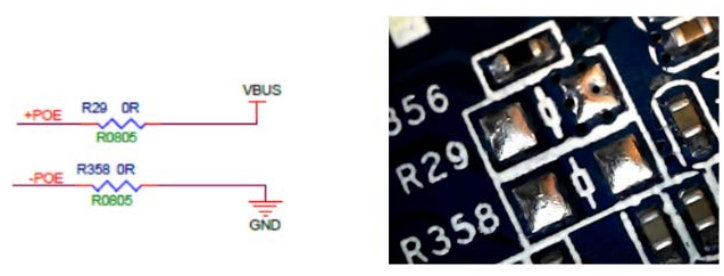

Fig. 3. Power shunt Resistors R29 and R358.

By default, the circuit board does not have resistors R29 and R358 installed, and their sockets are empty. To achieve POE with the required voltage, the R358 socket needs to be short circuited, but in the R29 socket a voltage decreasing regulator to $5 \mathrm{~V}$ is to be installed to safely power the board itself.

Now the Orange Pi zero is primed to be linked with elements with a lot higher voltage level.

Using the modules described above, a prototype of the system was created (see Fig. 4), which consists of the following parts: Orange Pi zero module.

1. POE voltage decreasing regulator $6-45 \mathrm{~V}$ to 5V 5A;

2. Power distribution bord with $5 \mathrm{~V} 3.3 \mathrm{~V}$ and I2C connectors;

3. Impedances measuring module I2C;

4. UART keyboard;

5. Temperature and humidity sensors. I2C.

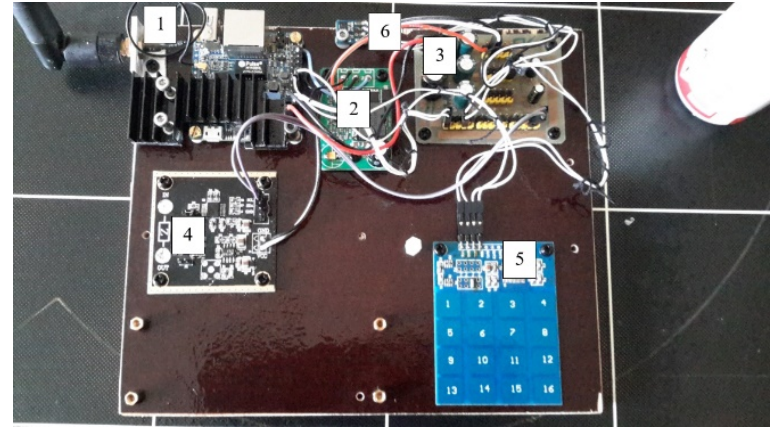

Fig. 4. Orange Pi zero with modified power supply and installed distribution connections for the measurement of impedance.

Another very promising one is a Linux based minicomputerthe "Onion Omega2+ Linux Compute Module". It is priced just over \$ 10 with built-in Wi-Fi. It is offered as an independent daughter board, the power can be supplied via independent transformer/power supply connection or a separate RJ45 (POE), which is preferable for intended use. The size of the module measures $34 \times 20 \times 2.8 \mathrm{~mm}$ or $42.9 \times 26.4 \times 9.9 \mathrm{~mm}$ (see Fig. 5) depending on the modification. Powered with $3.3 \mathrm{~V}$ the minicomputer consumes 400 to $800 \mathrm{~mA}$. Following, if one $3.7 \mathrm{~V}$ Li-ion $18650 \mathrm{~mA}$ battery would be used, the board could work for 6-9 hours continuously.

Comparing the relevant properties, the Onion Omega family products are preferred over Orange Pi zero. Since both Onion and Orange microcomputers are Linux based, switching from one to the other is viable.

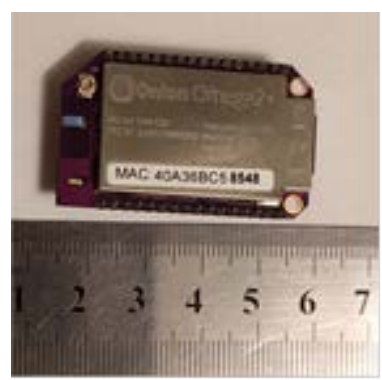

Fig. 5. Onion Omega2+ Linux Compute Module

\section{CONCLUSION}

The objective of the project is to develop a new technology that utilizes a reference-free principle of assessment of the monitoring results. Though the Orange Pi solution requires some manual modification to adjust it to the POE requirements, this modification also provides the system with flexibility not found in the default configuration of any other stock computing solution due to ability to provide higher or lower POE voltages, while the Onion Omega has RJ45 by default, allowing easier installation, though provide only default voltage values. The modified computing system has numerous applications when used in conjunction with wired, wireless and even LTE communications. The results and, as a proxy, the price, of any method used, will highly depend on how well-placed sensory elements and modules are and how effective they work together. According to the project plan, practical experiments are still scheduled for a later date. The experiments will allow to further test the method and to better optimize it for future applications, such as in the field of aviation and industrial objects and fields. 


\section{ACKNOWLEDGMENTS}

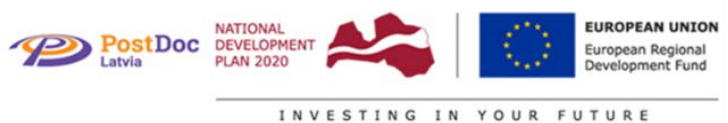

This work has been supported by the European Regional Development Fund within the Activity 1.1.1.2 "Postdoctoral Research Aid" of the Specific Aid Objective 1.1.1 "To increase the research and innovative capacity of scientific institutions of Latvia and the ability to attract external financing, investing in human resources and infrastructure" of the Operational Program "Growth and Employment” (No. 1.1.1.2/VIAA/2/18/326).

\section{REFERENCES}

[1] Giurgiutiu, V., Structural Health Monitoring with Piezoelectric Wafer Active Sensors, Elsevier Academic Press, Amsterdam \& Boston, 760 (2008).

[2] Yan, W., Chen, W. Q., Cai, J. B. and Lim, C. W., "Quantitative structural damage detection using high-frequency piezoelectric signatures via the reverberation matrix method,” Int. J. Num. Meth. Eng., 71(5), 505-528 (2007).

[3] Annamdas, V. G. M. and Soh, Ch. K., "Application of Electromechanical Impedance Technique for Engineering Structures: Review and Future Issues,” J. Intell. Mat. Syst. and Struct., 21, 41-59 (2010).

[4] Pavelko, V. New Applications of a Model of Electromechanical Impedance for SHM. In: Health Monitoring of Structural and
Biological Systems 2014, United States of America, San Diego, 9 13 March, 2014. Bellingham: SPIE, 2014, pp.90640Y-1-90640Y15. ISBN 978-0-8194-9990-5. Available from: doi:10.1117/12.2044260

[5] Pavelko, V. Application of the Fatigue Crack Opening/Closing Effect for SHM Using Electromechanical Impedance Technology. Applied Mechanics and Materials, 2015, Vol. 811, pp. 228-235. ISSN 1660-9336. e-ISSN 1662-7482. Available from: doi: 10.4028/www.scientific.net/AMM.811.228.

[6] Pavelko, V. Application of the Fatigue Crack Opening/Closing Effect for Aircraft SHM. In: 7th International Symposium on NDT in Aerospace: Proceedings, Germany, Bremen, 16-18 November 2015. Bremen: 2016, pp. 1-8. ISSN 1435-493.

[7] Abdulwadood Al-Ali, Ahmad Elwakil, Abdelaziz Ahmad and Brent Maundy; "Design of a Portable Low-Cost Impedance Analyzer", Proceedings of the 10th International Joint Conference on Biomedical Engineering Systems and Technologies (BIOSTEC 2017), pp. 104-109, 2017.

[8] Venu Gopal Madhav Annamdas, Yaowen Yang, Chee Kiong Soh, "Impedance based Concrete Monitoring using Embedded PZT Sensors”, International journal of civil and structural engineering, Volume 1, No. 3, 2010.

[9] Brodnevs, D., Hauka, M. Method for Estimating Delays in Parallel Redundant Data Transfer Networks. In: 2019 IEEE 60th International Scientific Conference on Power and Electrical Engineering of Riga Technical University (RTUCON 2019): Conference Proceedings, Latvia, Riga, 7-9 October, 2019. Piscataway: IEEE, 2019, pp.395-398. ISBN 978-1-7281-3943-2. eISBN 978-1-7281-3942-5. Available from: doi:10.1109/RTUCON48111.2019.8982265 